\title{
Chemotherapy versus support cancer treatment in advanced gastric cancer: a meta-analysis
}

\section{Casaretto, P.L.R. Sousa and J.J. Mari}

Programa em Saúde e Comportamento, Psicologia Médica, Pontifícia Universidade Católica de Pelotas, Pelotas, RS, Brasil

\section{Correspondence \\ L. Casaretto \\ Pontifícia Universidade Católica \\ de Pelotas \\ Rua Cassiano, 58 \\ 96015-700 Pelotas, RS \\ Brasil \\ E-mail: Ipcasa@brturbo.com}

Part of a Master's thesis presented by L. Casaretto to the Pontifícia Universidade Católica de Pelotas, Pelotas, RS, Brazil.

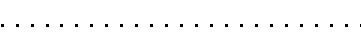

Received September 22, 2004 Accepted November 18, 2005

\begin{abstract}
The aim of the present study was to compare the efficacy of chemotherapy and support treatment in patients with advanced non-resectable gastric cancer in a systematic review and meta-analysis of randomized clinical trials that included a comparison of chemotherapy and support care treatment in patients diagnosed with gastric adenocarcinoma, regardless of their age, gender or place of treatment. The search strategy was based on the criteria of the Cochrane Base, using the following key words: 1) randomized clinical trials and antineoplastic combined therapy or gastrointestinal neoplasm, 2) stomach neoplasm and drug therapy, 3) clinical trial and multi-modality therapy, 4) stomach neoplasm and drug therapy or quality of life, 5) doubleblind method or clinical trial. The search was carried out using the Cochrane, Medline and Lilacs databases. Five studies fulfilled the inclusion criteria, for a total of 390 participants, 208 (53\%) receiving chemotherapy, $182(47 \%)$ receiving support care treatment and 6 losses $(1.6 \%)$. The 1-year survival rate was $8 \%$ for support care and $20 \%$ for chemotherapy $(\mathrm{RR}=2.14,95 \% \mathrm{CI}=1.00-4.57, \mathrm{P}=0.05)$; $30 \%$ of the patients in the chemotherapy group and $12 \%$ in the support care group attained a 6-month symptom-free period $(\mathrm{RR}=2.33,95 \%$ $\mathrm{CI}=1.41-3.87, \mathrm{P}<0.01)$. Quality of life evaluated after 4 months was significantly better for the chemotherapy patients $(34 \% ; \mathrm{RR}=2.07$, $95 \% \mathrm{CI}=1.31-3.28, \mathrm{P}<0.01)$ with tumor mass reduction $(\mathrm{RR}=3.32$, $95 \% \mathrm{CI}=0.77-14.24, \mathrm{P}=0.1)$. Chemotherapy increased the 1-year survival rate of the patients and provided a longer symptom-free period of 6 months and an improvement in quality of life.
\end{abstract}

Key words

- Gastric cancer

- Systematic review

- Combined antineoplastic therapy

- Cancer support treatment

- Meta-analysis

- Chemotherapy

\section{Introduction}

Adenocarcinoma is the most common kind of gastric cancer, accounting for up 90 to $95 \%$ of this type of neoplasia. About $65 \%$ of patients with gastric cancer are over 50 years of age, with incidence peaking at age 70. According to the National Cancer Institute (INCA), 20,640 new cases of gastric cancer were predicted to occur in Brazil during 2003. Gastric cancer has the fourth highest mortality rate with a predicted value of 11,145 deaths per year (INCA, www.inca. gov.br, Ref. 1).

During the 70's some investigators (2-6) mentioned an improvement in advanced gastric cancer with the use of chemotherapy, but few articles compared chemotherapy with 
supportive treatment care. A decline in the incidence of gastric cancer has been observed in developed countries such as the United States and the United Kingdom. The highest mortality rate is found in Latin America, mainly in Costa Rica, Chile and Colombia. Nevertheless, Japan is the country with the highest rate of gastric cancer, with 780 cases per 100,000 inhabitants (UICC, www. uicc.org, 2003).

An increased number of patients are being diagnosed with gastric cancer when the disease is in an advanced stage due to the silent symptoms of the disease during its early stages. According to the WHO, supportive treatment is the sole care given to patients whose disease no longer responds to curative treatment. This consists of active and full-time assistance in order to guarantee the best possible quality of life not only to the patients, but also to their families. Surgery is part of the process and demands an evaluation of clinical conditions, nature of symptoms and therapeutic procedures that can induce similar responses with minimum risk (1). Nutritional, psychological and clinical (hydration, analgesia) support are all part of the palliative care. The aim of the present study was to conduct a systematic review of the literature to evaluate the efficacy of chemotherapy and support treatment in patients with advanced non-resectable gastric cancer.

\section{Search strategy}

The search strategy identified randomized clinical trials (RCTs) that compared chemotherapy with supportive treatment in advanced gastric cancer patients. Electronic databases such as Cochrane Controlled Trials, Lilacs, Medline, and Pain-Relief Cochrane Group were used, as well as the following terms: RCT and (antineoplastic combined therapy or gastrointestinal neoplasm) or stomach neoplasm or drug therapy; clinical trial and (multi-modality therapy or stomach neoplasm) drug therapy or quality of life; stomach neoplasm and (combined modality therapy) or double-blind method or clinical trial; gastric neoplasias and (therapeutic procedures) or chemotherapy or palliative care. There were no restrictions concerning gender, age, clinical conditions, or previous care.

An attempt to contact all authors of the relevant reviews was made in order to obtain information on other available clinical reviews that had not been published as yet or had not been retrieved by the regular retrieval system, or on-going studies. Searches were made in specialized journals and in chapters of books that mentioned the subject. In order to identify any possible new RCTs, all cited references within these articles, for example included and excluded studies, were checked.

\section{Outcomes}

All RCTs comparing chemotherapy with supportive care for the treatment of advanced gastric cancer were included in the study. The main outcomes of interest for this review were defined as follows:

i) Survival: one of the objectives of the antineoplastic therapy is to allow patients to survive as long as possible with the same quality of life that they would have had if they had not been patients with neoplasias. From a practical and ethical point of view it is not possible to wait until the patients present an appropriate quality of life in order to provide a feed-back on the efficacy of a given treatment. Survival is used as an objective measure of the antineoplastic effect.

ii) Improvement in quality of life: the subjective changes are understood to be those that can be detected only by the patient. A subjective improvement is frequently followed by an objective improvement. This outcome was demonstrated by at least $50 \%$ of those showing symptoms of subjective 
improvement.

iii) Symptom-free period: defined as the time during which there were no symptoms of the disease.

iv) Objective response to treatment: defined by the criteria of the World Health Organization (WHO) (7) and referred to as an improvement in the reduction of the dimensions of the tumor mass.

\section{Quality of the studies}

The criteria (A, B, C) suggested by the Cochrane Handbook were used to evaluate the methodological quality of the RCTs. Such criteria are based on the evidence of a strong correlation between bias and allocation concealment (8). In this manner, three quality groups can be defined as follows: 1) low bias (allocation concealment performed in a correct manner), 2) moderate bias (uncertainty about the masking of randomization), 3) high bias (inappropriate masking of the randomization process). Consequently, level C studies were excluded. The Jadad scale was used with the aim of determining accuracy in the evaluation based solely on the randomization process, according to the criteria of the Cochrane Handbook. The number three was used as the cut-off point.

Two investigators (L. Casaretto and J.J. Mari) extracted the data concerning the characteristics of the participants, details on the interventions and the main outcomes of the cases studied. Calculations were performed using the statistical program RevMan 4.2. The relative risk (RR), with random effect, was calculated for the dichotomous variables of therapeutic response, with a result uncertainty expressed via an estimate of the 95\% confidence interval (CI) around this measure. As an absolute measure, the number need to treat (NNT) was calculated with a $95 \% \mathrm{CI}$, taking into account the estimate of the event in the control group (9-14). The results were evaluated in a meta-analysis table.

\section{Results}

A total of 882 references were identified. One of the authors (L. Casaretto) evaluated the summary of each reference. Eight articles (2-5,15-18) were selected. Two of them $(2,3)$ from references in the Clinic Oncology book by Abeloff (19) and the remaining six from Medline. The other references were excluded because 1) they did not show the RCT design, 2) the mentioned RCTs compared two or more methods of chemotherapy, 3) the RCTs that compared chemotherapy with support care included tumors other than gastric tumors, or 4) the number of gastric neoplasms was not stated. Finally, RCTs that compared gastric cancer with a therapeutic modality other than chemotherapy were also excluded.

Two of the eight selected articles were excluded because they concerned the results of the same protocol published during three different time intervals. The article selected was the most recently published one and included the previous data $(17,18)$. Consequently, on completion five articles had been included with at least one result dealing with efficiency.

Regarding the structure of the study, all of the articles contained two groups of patients who either underwent chemotherapy or supportive care. The randomized patients in the five articles underwent treatment as outpatients and in the fifth article inpatients were also included. Three studies were from a single center trial $(2,3,5)$ and the other two were multicenter studies $(4,15)$. As far as random selection was concerned, two of them mentioned random allocation in a double-blind manner $(3,15)$. The other three failed to report their masking method. One study discontinued randomization after 3 months due to the evidence of considerable improvement within the chemotherapy group (2). As to follow-up, the minimum evaluation period for randomized patients was set at 3 months (2) and the maximum period at 71 months (3). 


\section{Participants}

All 390 participants had histologically proven adenocarcinoma of the stomach. The ages of the participants were similar in all groups, with the oldest enrolled patient being 75 years. In one article, patients who were in the chemotherapy group were divided into two subgroups, i.e., patients under and over 60 years of age. In these patient subgroups, the chemotherapy scheme varied according to patient age (4).

The number of participants who showed survival improvement was the most important result in the papers. For the articles in which the absolute number of patients was not reported, this number was deduced from the tables included in the papers $(2-5,15)$. The evaluation of continuous improvement was not carried out because of data omission in these studies.

Three studies were classified as A (3-5) according to the Cochrane Handbook (8) criteria and the other two were classified as B (2, 15). With reference to the Jadad classification (8), two of these studies had a classification value of $3(2,15)$ and the other three scored 5 (3-5). Intention to treat was only mentioned in three of the studies (2-4) (Table 1).

\section{Survival}

Survival was evaluated in all of the five studies included $(2-5,15)$ and the assessment was made after 3,6 , and 12 months. Intention to treat was mentioned in three studies (2-4). The survival curves were calculated using the Kaplan-Meier method in two studies $(4,15)$ and by the log-rank test in the other three $(2,3,5)$. Only one study (15) mentioned the use a logarithmic scale for this evaluation.

One of the studies used the Cox proportional hazards regression model (4) to compensate for the differences in the clinical and pathological characteristics among the participants. Another study (15) used the chi- square test and the Student $t$-test to compare the characteristics of the participants. The participants of the five studies whose relative numbers were presented in the tables had their absolute number estimated for a meta-analysis calculation.

The survival analysis at 3 months was reported for all five studies and the total number of participants for this analysis was 390 . Of these, 240 survived, 110 in the supportive care group and $130 \mathrm{in}$ the chemotherapy group, with respective survival rates of 55 and $62 \%$ $(\mathrm{RR}=1.08 ; 95 \% \mathrm{CI}=0.86-1.36 ; \mathrm{P}=0.50)$. The survival analysis after 6 months was included in case studies $(3-5,15)$. One of them (2) was excluded because the randomization was discontinued after a 3-month period. A total of 368 participants were included in this analysis. Of these, 117 survived up to the 6th month, 44 in supportive care and 73 in chemotherapy. The survival rates were 25 and $37 \%$, respectively $(\mathrm{RR}=1.49 ; 95 \% \mathrm{CI}=0.88-2.53$; $\mathrm{P}=0.14$ ) showing no statistical difference between groups and with a positive test of heterogeneity $(\mathrm{P}<0.05)$. When sensitivity analysis was performed, homogeneity was obtained by excluding the Kingston et al. (15) study, since it included inpatients and outpatients with performance status $>2$ and Karnofski $<60 \%$. There was a statistically significant difference favoring the chemotherapy group $(\mathrm{RR}=1.83 ; 95 \% \mathrm{CI}=1.10-3.04 ; \mathrm{P}<0.02$; $\mathrm{NNT}=8.57 ; 95 \% \mathrm{CI}=6.0-15.0)$.

The survival analysis after 12 months was carried out in 4 case studies $(3-5,15)$. A total of 368 patients were assessed in this analysis, 172 in supportive care and 196 in chemotherapy. The survival rates for this period were 8 and $20 \%$, respectively $(\mathrm{RR}=$ $2.14 ; 95 \% \mathrm{CI}=1.00-4.57 ; \mathrm{P}=0.05 ; \mathrm{NNT}=$ $10.37 ; 95 \% \mathrm{CI}=6.83-21.52$ ), favoring the chemotherapy group (Table 2).

\section{Quality of life}

Analysis of the results was carried out after the 4th month of accrual in all 5 case 
studies. In one article (2), quality of life was analyzed by the toxicity outcome according to WHO (7) criteria, but the article mentioned toxicity related to chemotherapy. Pyrhonen et al. (3) mentioned evaluation of the quality of life, but there were neither absolute nor relative values for the calculation in the meta-analysis. Consequently, only two articles $(4,15)$ were included in this anal- ysis, with the absolute number of patients estimated from the tables. A total of 254 patients were included in the analysis, 64 of whom improved their quality of life, 43 in chemotherapy and 21 in supportive care (RR $=2.07 ; 95 \% \mathrm{CI}=1.31-3.28 ; \mathrm{P}<0.01)$. This difference showed a statistically significant improvement in the quality of life for the chemotherapy patients (Table 3 ).

Table 1. Survival.

Review: Chemotherapy versus support cancer treatment in advanced gastric cancer: a meta-analysis Comparison: 1 chemotherapy versus supportive care treatment Outcome: 1 survival

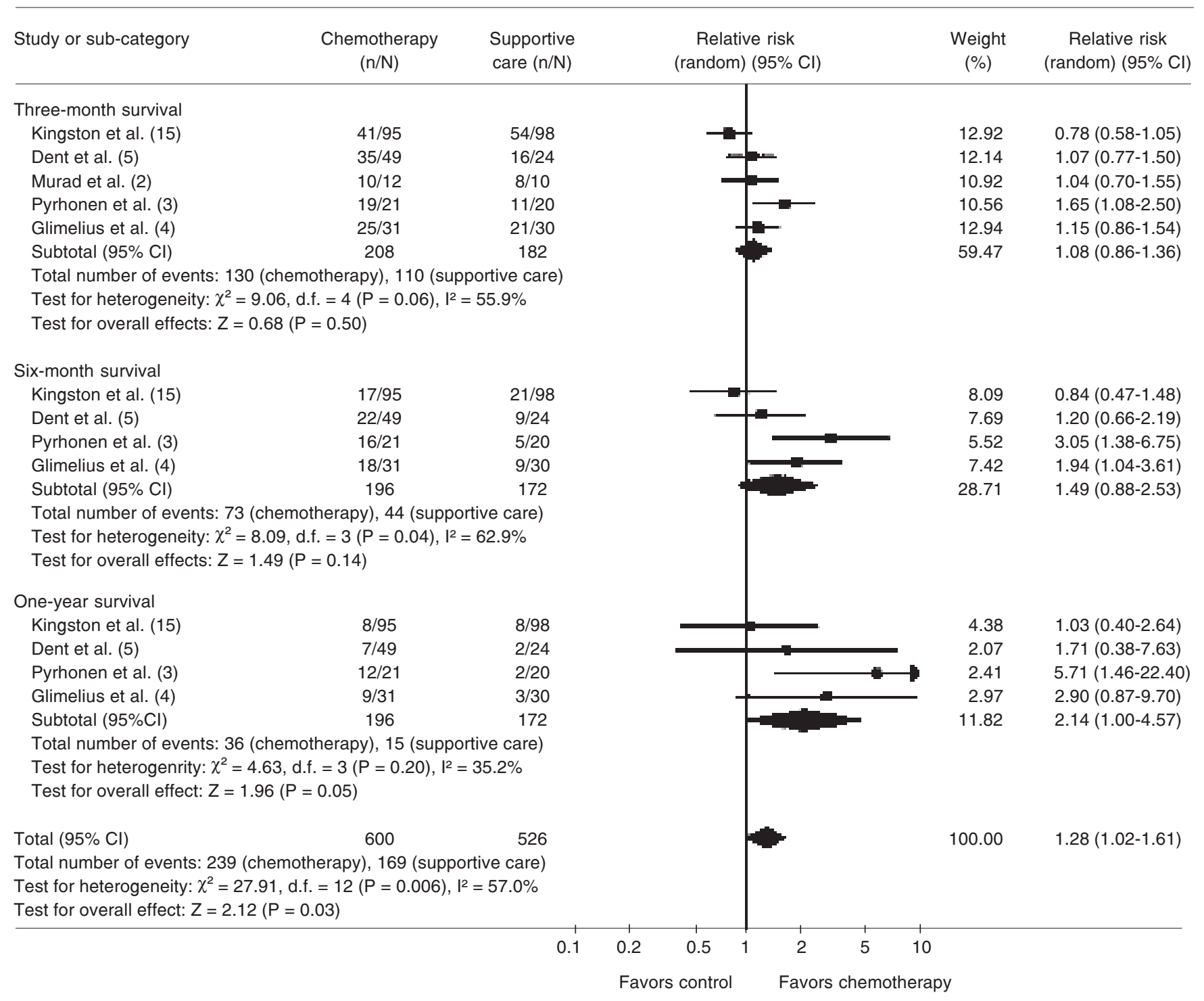




\section{Symptom-free period}

The symptom-free period was mentioned as the survival period exempt from any disease progression that could be evaluated by measuring lesions. Three case studies $(3,4,15)$ were included and the absolute values for calculation using meta-analysis were estimated from the charts and tables. A total of 295 patients took part in the analysis; 104 of them did not show progression after 6 months, $43(29 \%)$ in the chemotherapy group and 18 $(12 \%)$ in the supportive care group. The mean time of analysis was 24 weeks $(\mathrm{RR}=$ $2.33 ; 95 \% \mathrm{CI}=1.41-3.87 ; \mathrm{P}<0.01)$ and was significantly longer for the chemotherapy group (Table 4).

\section{Clinical response}

The objective responses were evaluated as a dichotomous variable according to the criteria of the International Union Against Cancer (UICC) (8). The clinical responses could include any of the consequences of the therapeutic response, but it would have been referred to as the presence or absence of any tumor remission (objective response). Three case studies were included in this comparison $(3,4,15)$. One study $(5)$ was excluded due to

Table 2. Improved quality of life.

Review: Chemotherapy versus support cancer treatment in advanced gastric cancer: a meta-analysis

Comparison: 1 chemotherapy versus support care treatment

Outcome: 2 improved quality of life

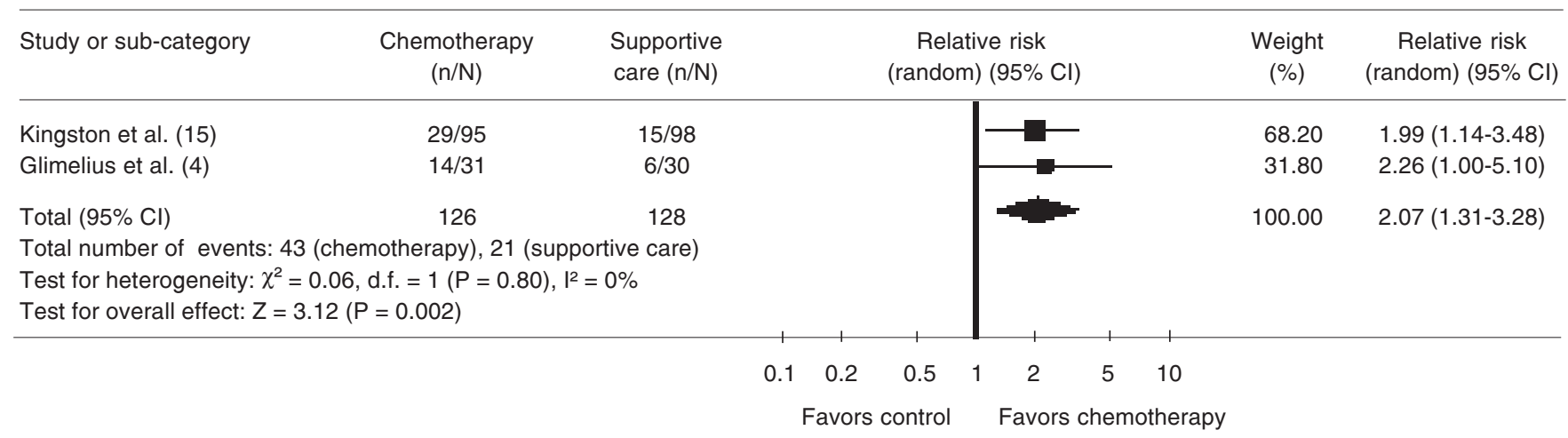

Table 3. Symptom-free periods.

Review: Chemotherapy versus support care treatment in advanced gastric cancer: a meta-analysis

Comparison: 1 chemotherapy versus supportive care treatment

Outcome: 3 symptom-free period

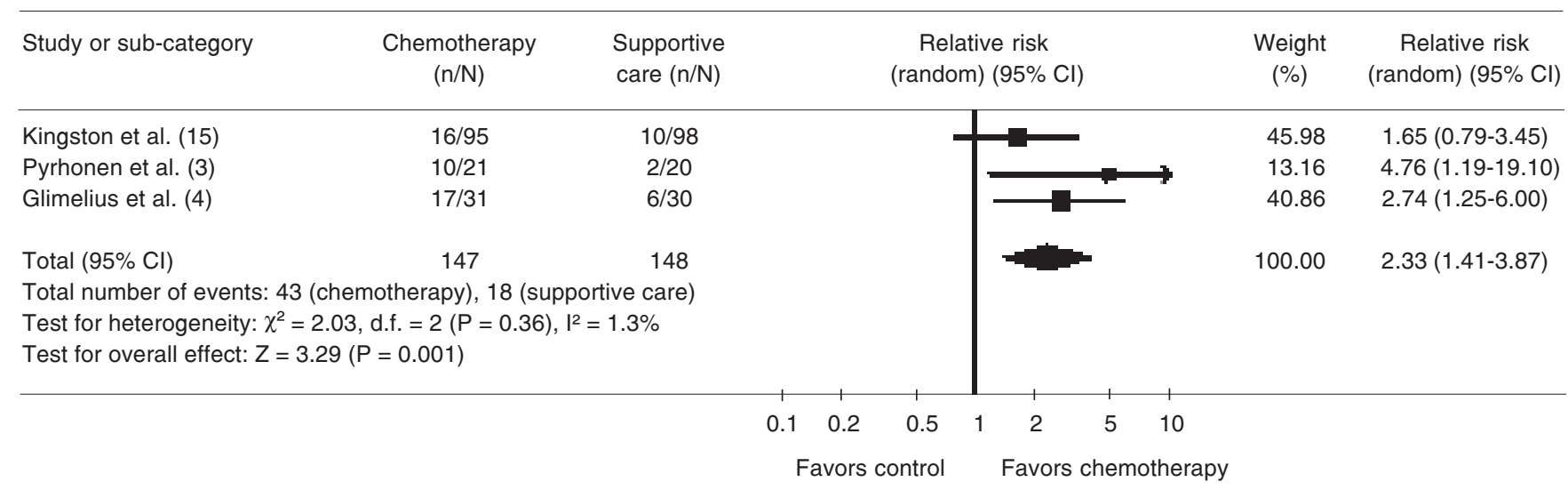


lack of evaluation of this type of result and another (2) due to the fact that the evaluation of the objective responses included both randomized and non-randomized patients. A total of 160 patients were included; 21 with a positive response to the intervention, $16(10 \%)$ in the chemotherapy group and $5(3 \%)$ in the supportive care group $(\mathrm{RR}=3.32 ; 95 \% \mathrm{CI}=$ $0.77-14.24 ; \mathrm{P}=0.11)$. This result did not differ significantly between groups (Table 5).

\section{Discussion}

Chemotherapy has been receiving increasing attention for the treatment of gastric cancer, but at an advanced stage it is still only accepted as palliative care (20-22). Some investigators (2-4) have been attempting to safeguard this approach as the choice of treatment for patients with advanced disease.

This review showed that chemotherapy, regardless of the methodology prescribed, but considering only the use of cytotoxic agents, provided a gain in survival detected by analysis after 6 and 12 months for patients undergoing chemotherapy, with a statistically significant difference between the two groups. The sensitivity analysis attempted to explain the heterogeneity found among the case studies and demonstrated that inclusion of patients with the worst clinical conditions (performance status $>2$ and Karnofski $<60 \%)(5,15)$ has a direct influence on survival when analyzed in conjunction with patients in better clinical condition (23). Moreover, patients undergoing chemotherapy benefited from treatment, showed significant improvement in quality of life and had a longer symptom-free period of 6 months compared to only a maximum of 3 months for the supportive care group. The objective responses to treatment, evaluated after 4 months, did not show any significant difference between the two groups; the study of Kingston et al. (15) analyzed a subset of patients that had a palpable mass, and this partial analysis did not indicate any influence of chemotherapy on the clinical response.

A strategy directed towards identifying every RCT, either published or unpublished, which evaluated the treatment of advanced gastric cancer by comparing supportive care with chemotherapy treatment regardless of the chemotherapy protocol used, was the objective of the present study. Overall, the methodological quality of the studies was appropriate. However, some methodological flaws may be pointed out such as 1) the absence of a detailed report of the randomization process and the procedures used to conceal it; 2) the term analysis by intention

Table 4. Objective responses.

Review: Chemotherapy versus support care treatment in advanced gastric cancer: a meta-analysis Comparison: 1 chemotherapy versus supportive care treatment

Outcome: 4 objective responses

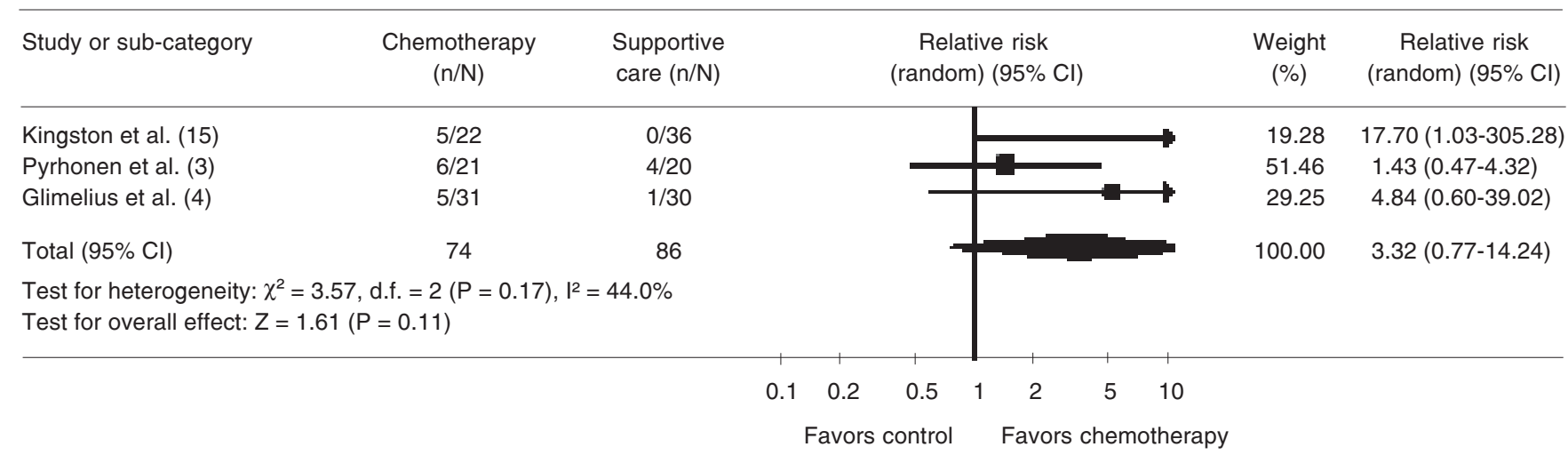


Table 5. Characteristics of the studies surveyed.

\begin{tabular}{|c|c|c|c|c|c|c|}
\hline Study & Methods & Participants & Interventions & Outcomes & Notes & Allocation \\
\hline Dent et al. (5) & $\begin{array}{l}\text { Monocentric } \\
\text { RCT } \\
\text { allocation, } \\
\text { sealed } \\
\text { envelopes with } \\
\text { informed consent, } \\
\text { Time: Jan } 74 \\
\text { to Jun } 76\end{array}$ & $\begin{array}{l}\mathrm{N}=142 \\
\text { Div. II (patients with } \\
\text { advanced disease), } \\
\mathrm{N}=76 \\
\mathrm{CT} \text { (tiotepa), } \mathrm{N}=26 \\
\mathrm{CT}(5 \mathrm{FU})+\mathrm{RT}, \mathrm{N}=24 \\
(\mathrm{n}(\mathrm{CT})=50) \\
\mathrm{BSC}, \mathrm{N}=26 \\
\text { Dropouts, } \mathrm{N}=3 \\
\mathrm{BSC}, \mathrm{N}=2 \\
\mathrm{CT}+\mathrm{RT}, \mathrm{N}=1 \\
\text { Only ambulatory } \\
\text { patients. } \\
\text { Mean age: } 65 \text { years } \\
\text { Sex (M/F): } 1 / 1\end{array}$ & $\begin{array}{l}N=73 \\
\text { Tiotepa, } N=26 \\
\text { FU+RT, } N=23 \\
N=49 \\
\text { BSC, } N=24\end{array}$ & $\begin{array}{l}\text {-Survival } \\
\text { correlated with TNM } \\
\text { stage of disease and } \\
\text { not therapy } \\
\mathrm{P}>0.5 \\
90 \% \text { dead in } \\
1 \text { year. } \\
\text {-Quality of life } \\
\text { No difference } \\
\text { between treatment } \\
\text { groups }\end{array}$ & $\begin{array}{l}90 \% \text { of patients } \\
\text { dead at } 1 \text { year } \\
\text { Not clear about } \\
\text { ITT. } \\
\text { Jadad } 3\end{array}$ & $\begin{array}{c}\text { B } \\
\text { unclear }\end{array}$ \\
\hline Glimelius et al. (4) & $\begin{array}{l}\text { Multicentric } \\
\text { RCT allocation, } \\
\text { aleatory. } \\
\text { Analysis by ITT } \\
\text { Time: Jan } 91 \\
\text { to Feb } 95 \\
\text { (4 years, } 1 \text { month) }\end{array}$ & $\begin{array}{l}\mathrm{N}=61 \\
\text { ELF/LvF-31 } \\
\text { BSC = 30 } \\
\text { Dropouts: } 0 \\
\text { Ambulatory } \\
\text { Mean age: } 64 \text { years } \\
\text { Sex (M/F): } 4 / 1\end{array}$ & $\begin{array}{l}\mathrm{ELF} / \mathrm{LvF}, \mathrm{N}=31 \\
\mathrm{BSC}=30\end{array}$ & $\begin{array}{l}\text {-Improved quality } \\
\text { of life } \\
\text { ELF/LvF-14/31 } \\
(45 \%) \\
\text { BSC-6/31 (20\%) } \\
\mathrm{P}<0.05 \\
\text {-Survival } \\
\text { ELF/LvF - } 6 \text { months } \\
\text { BSC - } 2 \text { months } \\
\text {-Disease-free time in } \\
6 \text { months } \\
\text { ELF/LvF-17/55\% } \\
\text { BSC-6/20\% } \\
P<0.01\end{array}$ & $\begin{array}{l}\text { Quality of life } \\
\text { and survival } \\
\text { were better in } \\
\text { the chemotherapy } \\
\text { group. } \\
\text { Jadad } 5\end{array}$ & $\begin{array}{c}\mathrm{A} \\
\text { adequate }\end{array}$ \\
\hline Kingston et al. (15) & $\begin{array}{l}\text { Multicentric } \\
\text { RCT allocation, } \\
\text { aleatory, } \\
\text { double-blind, } \\
\text { controlled } \\
\text { Time: Oct } 74 \\
\text { to Feb } 76 \\
\text { (1 year, } 4 \text { months) }\end{array}$ & $\begin{array}{l}\mathrm{N}=193 \\
\mathrm{CT}, \mathrm{N}=95 \\
\mathrm{BSC}, \mathrm{N}=98 \\
\text { Included ambulatory } \\
\text { and hospital } \\
\text { with } \mathrm{PS}>2 \text {, } \\
\text { Karnofski }<60 \% \text {, } \\
\text { Mean age: } 67 \text { years } \\
\text { Sex (M/F): } 2 / 1\end{array}$ & $\begin{array}{l}\mathrm{N}=200 \\
\text { Dropouts: } \mathrm{N}=2, \\
\text { follow-up, } 7 \\
\text { patients excluded } \\
\text { because } \\
\text { post-mortem } \\
\text { analysis showed } \\
\text { no gastric cancer } \\
\text { Dropouts: } \mathrm{N}=7 \\
5 \mathrm{FU}, \mathrm{N}=56 \\
\mathrm{CCNU} \text { and } 5 \mathrm{FU}, \\
\mathrm{N}=39 \\
\mathrm{Placebo}, \mathrm{N}=98\end{array}$ & $\begin{array}{l}\text {-Quality of life } \\
\text { placebo } 33 \\
5 \text { FU-21 } \\
5 \text { FU and } \\
\text { CCNU-32 } \\
\text {-One-year survival: } \\
\text { CT-8\%, } \\
\text { BSC-8\% } \\
\text {-Objective response } \\
\text { CT-5/22, } \\
\text { BSC-0/36 }\end{array}$ & $\begin{array}{l}\text { Calculated overall } \\
\text { rates did not } \\
\text { reveal difference } \\
\text { between groups } \\
\text { in patient survival } \\
\text { curves. } \\
\text { Not clear about ITT. } \\
\text { Jadad } 3\end{array}$ & $\begin{array}{c}\text { B } \\
\text { unclear }\end{array}$ \\
\hline Murad et al. (2) & $\begin{array}{l}\text { Monocentric } \\
\text { RCT allocation } \\
\text { Analysis by ITT } \\
\text { Time: Jan } 88 \text { to } \\
\text { Dec } 91 \\
\text { (3 years, } \\
11 \text { months) }\end{array}$ & $\begin{array}{l}\mathrm{N}=41 \\
22 \text { randomized, } \\
19 \text { randomized } \\
\text { direct by } \\
\text { chemotherapy } \\
\text { group } \\
\text { FAMTX-31 } \\
\text { BSC-10(GC) } \\
\text { Mean age: } 55 \text { years } \\
\text { Sex }(M / F): 2 / 1\end{array}$ & $\begin{array}{l}\text { FAMTX, N=31 } \\
\text { BSC, } N=10\end{array}$ & $\begin{array}{l}\bullet \text { One-year survival: } \\
\text { FAMTX-40\% } \\
\text { Two years - } \\
\text { FAMTX-10\% } \\
\text { •Overall survival } \\
\text { FAMTX - } 10 \text { months } \\
\text { BSC - } 3 \text { months } \\
P<0.001\end{array}$ & $\begin{array}{l}\text { In this trial } \\
\text { the patients } \\
\text { were randomized } \\
\text { after } 22 \text { patients, } \\
\text { direct in } \\
\text { chemotherapy } \\
\text { group. } \\
\text { Jadad } 3\end{array}$ & $\begin{array}{c}\text { B } \\
\text { unclear }\end{array}$ \\
\hline & & & & & \multicolumn{2}{|c|}{ Continued on next page } \\
\hline
\end{tabular}


Table 5 continued.

\begin{tabular}{|c|c|c|c|c|c|c|}
\hline Study & Methods & Participants & Interventions & Outcomes & Notes & Allocation \\
\hline Pyrhonen et al. (3) & $\begin{array}{l}\text { Monocentric, } \\
\text { RCT, allocation } \\
\text { randomized by a } \\
\text { sealed envelope } \\
\text { method and } \\
\text { permutated blocks } \\
\text { Analysis by ITT, } \\
\text { double-blind, } \\
\text { with informed } \\
\text { consent } \\
\text { Time: Jul } 86 \text { to } \\
\text { Jun } 92 \text { ( } 5 \text { years, } \\
11 \text { months). }\end{array}$ & $\begin{array}{l}N=41 \\
C T(F E M T X), N=21 \\
\text { BSC, } N=20 \\
\text { Mean age: } 60 \text { years } \\
\text { Sex }(M / F): 1 / 1\end{array}$ & $\begin{array}{l}\text { FEMTX, N }=21 \\
\text { BSC, } N=20\end{array}$ & 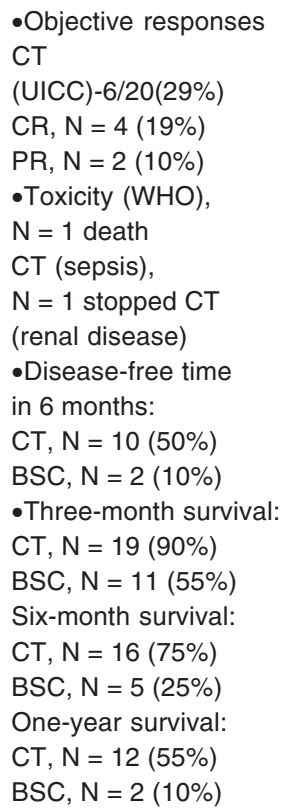 & $\begin{array}{l}\text { In this trial the } \\
\text { patients were } \\
\text { allocated by a } \\
\text { sealed envelope } \\
\text { method and } \\
\text { random } \\
\text { permutated blocks } \\
\text { were used. } \\
\text { Jadad } 5\end{array}$ & $\begin{array}{c}\mathrm{A} \\
\text { adequate }\end{array}$ \\
\hline
\end{tabular}

The Jadad scale was used with the aim of determining accuracy in the evaluation based solely on the randomization process. The Cochrane Handbook criteria were used for allocation: $\mathrm{A}=$ adequate; $\mathrm{B}=$ unclear. TNM = tumor-nodulus-metastasis; ITT $=$ intention to treat; $\mathrm{CT}=$ chemotherapy; $\mathrm{FU}=$ fluorouracil; RT = radiotherapy; $5 \mathrm{FU}=5$-fluorouracil; BSC $=$ best supportive care; ELF/LvF = etoposide, leucovorin, fluorouracil; RCT = randomized clinical trial; $\mathrm{CCNU}=$ Lomustine; FAMTX = fluorouracil-doxorubicin-methotrexate; FEMTX = fluorouracil-epidoxorubicin-methotrexate; UICC = International Union Against Cancer; $\mathrm{CR}=$ complete remission; $\mathrm{PR}=$ partial response. $\mathrm{PS}=$ performance status, Zubrod scale: PS $0=$ normal activity; PS 1 = disease symptoms, maintains daily activities; PS 2 = bedridden less than $50 \%$ of time, performs some activities; PS $3=$ bedridden more than $50 \%$ of time, dependent for care; PS 4 = completely bedridden, dependent on continuous care.

to treat was used, but in the final analysis there was no mention as to whether the losses were indeed included; 3 ) the absolute number of patients at the end of the evaluation of the results was not stated and had to be computed from the charts included in the studies; 4) the pairing methods of the comparison groups used were not fully specified, consequently leading to concerns about the evaluation method of the differences in the survival curves, a method that was described in all of the studies. This data set may conceal distortions, and therefore it would have been important to show the clinical and pathological characteristics of the participants as completely as possible, to better describe how their differences were distributed and to present the absolute and relative number of patients in tables and charts.

The present meta-analysis demonstrated that chemotherapy proved to be the treatment of choice for patients with advanced gastric cancer and the results clearly demonstrated its efficacy, with an increase in survival of over 1 year along with an improvement in the quality of life and a symptomfree period of over 6 months. New cytotoxic agents such as paclitaxel (24) and irinotecan (25) are currently being tested. Biological agents such as antiangiogenic agents (26) and monoclonal antibodies (27) with receptors for an epithelial growth factor may also be of assistance in the future for the treatment of this modality of neoplasm. 


\section{Acknowledgments}

We thank Dr. Luis Fernando Moreira, Clinical Hospital, Porto Alegre, RS, Brazil, for his valuable comments on earlier versions of this paper.

\section{References}

1. Instituto Nacional do Câncer (INCA). http://www.inca.org.br. Accessed February 12, 2004

2. Murad AM, Santiago FE, Petroianu A et al. (1993). Modified therapy with fluorouracil, doxorubicin and methotrexate in advanced gastric cancer. Cancer, 72: 37-41.

3. Pyrhonen S, Kuitunen T, Nyandoto P et al. (1995). Randomized comparison of fluorouracil, epidoxorubicin, and methotrexate (FEMTX) plus supportive care with supportive care alone in patients with non-resectable gastric cancer. British Journal of Cancer, 71: 587-591.

4. Glimelius B, Ekstrom K, Hoffman K et al. (1997). Randomized comparison between chemotherapy plus best supportive care with best supportive care in advanced gastric cancer. Annals of Oncology, 8: 163-168.

5. Dent DM, Werner ID, Novis B et al. (1979). Prospective randomized trial of combined oncological therapy for gastric carcinoma. Cancer, 44: 385-391.

6. Wils J (1996). The treatment of advanced gastric cancer. Seminars in Oncology, 23: 397-399.

7. World Health Organization (1979). Handbook for Reporting Results of Cancer Treatment. WHO offset publication No. 48. World Health Organization, Geneva, Switzerland.

8. Bireme. http://www.bireme.br. Accessed April 10, 2004.

9. Cox DR (1972). Regression models and life tables. Journal of the Royal Statistical Society, 34: 187-220.

10. Oken MM (1982). Toxicity and response criteria of the Easten Cooperative Oncology Group. American Journal of Clinical Oncology, 5: 649-651.

11. Lopes P (1999). Probabilidades e Estatística. Reichmann \& Affonso Editores, São Paulo, SP, Brazil.

12. Norell S \& Ahlbom A (1990). Introduction to Modern Epidemiology Foreword by Kenneth Rothman. ISBN 0-917227-06-9. Epidemiology Resources Inc., Chestnut Hill, MA, USA.

13. Fletcher RH (1996). Epidemiologia Clínica, Artes Médicas. 3rd edn. Artes Médicas, Porto Alegre, RS, Brazil.

14. Kirkwood BR (1994). Essentials of Medical Statistics. Blackwel Science, Oxford, UK.
15. Kingston RD, Ellis DJ, Powell J et al. (1978). The West Midland gastric carcinoma chemotherapy trial: planning and results. Clinical Oncology, 4: 55-69.

16. Park JO, Chung HC, Cho JY et al. (1997). Retrospective comparison of infusional 5-fluorouracil, doxorubicin and mitomycin-C (modified FAM) combination chemotherapy versus palliative therapy in treatment of advanced gastric cancer. American Journal of Clinical Oncology, 20: 484-489.

17. Glimelius B, Hoffman K, Graf W et al. (1994). Initial or delayed chemotherapy with best supportive care in advanced gastric cancer. Annals of Oncology, 5: 189-190.

18. Glimelius B, Hoffman K, Graf W et al. (1995). Cost-effectiveness of palliative chemotherapy in advanced gastrointestinal cancer. Annals of Oncology, 6: 267-274.

19. Abeloff MD (2000). Clinical Oncology. Chapter 60. 2nd edn. Churchil Livingstone, New York, 1545-1585.

20. O'Connell MJ (1985). Current status of chemotherapy for advanced pancreatic and gastric cancer. Journal of Clinical Oncology, 3: 10321041.

21. Kohne $\mathrm{CH}$ (2000). Developments in the treatment of gastric cancer in Europe. Oncology, 14: 22-25.

22. Cornelis JH (1998). The gastric cancer treatment controversy. Journal of Clinical Oncology, 21: 2282-2287.

23. National Comprehensive Cancer Network. http://www.nccn.org/. Accessed February 2, 2004.

24. Ajani JA, Fairweather J, Dumas P et al. (1998). Phase II study of Taxol in patients with gastric carcinoma. Cancer Journal from Scientific American, 4: 269-274.

25. Moehler M, Haas U, Siebler J et al. (2003). Weekly treatment with irinotecan, folinic acid and infusional 5-fluorouracil (IFL) in patients with advanced gastric cancer. Anticancer Drugs, 14: 645-650.

26. Cai H, Kong ZR \& Chen HM (2002). Matrix metalloproteinase-2 and angiogenesis in gastric cancer. Ai Zheng, 21: 25-28.

27. Kono K, Takahashi A, Ichihara F et al. (2002). Impaired antibodydependent cellular cytotoxicity mediated by herceptin in patients with gastric cancer. Cancer Research, 62: 5813-5817. 